\title{
bctA: a novel pBF4 gene necessary for conjugal transfer in Bacteroides spp.
}

\author{
Roderick M. Morgan and Francis L. Macrina \\ Author for correspondence: Francis L. Macrina. Tel: +1 804828 9728. Fax : +1 8048289946. \\ e-mail: MACRINA@GEMS.VCU.EDU
}

Department of

Microbiology and

Immunology, Box 980678

MCV Station, Virginia

Commonwealth University,

Richmond, VA 23298-0678,

USA

\begin{abstract}
PBF4 is a 41 kb conjugative R-plasmid that confers MLS (macrolide-lincosamidestreptogramin B) resistance in Bacteroides spp. To identify pBF4 genes governing conjugation, recombinational mutagenesis using a suicide vector carrying fragments of the pBF4 plasmid was employed. One of six independent insertion mutants of pBF4 isolated using this method was found to be conjugation-deficient. Nucleotide sequence analysis around the insertion site on this plasmid revealed a $2.8 \mathrm{~kb}$ ORF that encoded a putative $110 \mathrm{kDa}$ protein. A corresponding protein was observed when a 12 kb DNA fragment containing this ORF was used to program an in vitro transcription-translation system. Both the ORF and the predicted protein were novel when compared to available database sequences. This gene was designated bctA (Bacteroides conjugal transfer). Polyclonal rabbit antibodies that recognized a sub-sequence polypeptide of BctA reacted with a $55 \mathrm{kDa}$ protein in Western blot analysis using a total protein extract from Bacteroides fragilis containing pBF4. The protein was not present in a B. fragilis strain containing the conjugationdeficient insertion mutant of pBF4. The $55 \mathrm{kDa}$ protein was associated with the membrane fraction of $B$. fragilis. Although the cellular and biochemical basis of bctA-promoted conjugation remains unknown, this work demonstrates the existence of a heretofore unrecognized gene in bacterial conjugation, and the mutagenesis system used provides the means to isolate and characterize other genes involved in conjugal transfer in Bacteroides spp.
\end{abstract}

Keywords: conjugation, pBF4, bctA, Bacteroides fragilis, recombinational mutagenesis

\section{INTRODUCTION}

The cellular and molecular biology of bacterial conjugation are well-described for the $F$ plasmid of Escherichia coli (Ippen-Ihler \& Minkley, 1986; IppenIhler \& Manneewannakul, 1991; Ippen-Ihler \& Skurray, 1993). This paradigm has taught us that self-transmissible plasmids encode two major classes of genes which govern conjugal transfer. One group of genes encode components that specify the biosynthesis of donor pili. These surface appendages allow donor cells to specifically bind to recipient cells, forming mating pairs. Mating-pair formation leads to the union of

Abbreviations: MCS, multiple-cloning site; MLS, macrolide-lincosamidestreptogramin B.

The GenBank accession number for the sequence of the bctA gene and its flanking regions is U63096. cytoplasmic compartments permitting movement of DNA strands from donor to recipient. A second group of genes specify products that process and replicate plasmid DNA. Numerous plasmid gene products act in trans to implement this DNA processing, and a cisacting region called oriT also plays an important role. The oriT is the recognition site for proteins which work in concert to make a nick in the DNA creating the origin of a single-stranded plasmid DNA molecule which is translocated to the recipient cell. These elements of conjugal transfer, including the functionality of oriTlike sites, appear to be widely conserved among bacteria (Lanka \& Wilkins, 1995).

Molecular and cellular knowledge of conjugal transfer in Bacteroides spp. is lacking (Macrina, 1993). The three prototypic conjugative drug resistance plasmids of Bacteroides spp. are pBFTM10 (14.9 kb; also studied under the designation pCP1) (Tally et al., 1982; Matthews \& Guiney, 1986), pBF4 (41 kb) (Welch \& 
Table 1. Bacterial strains and plasmids

\begin{tabular}{|c|c|c|c|c|}
\hline \multirow[t]{2}{*}{ Strain /plasmid } & \multirow[t]{2}{*}{ Relevant characteristics } & \multicolumn{2}{|c|}{ Markers* expressed in: } & \multirow{2}{*}{ Reference/comments } \\
\hline & & E. coli & B. fragilis & \\
\hline \multicolumn{5}{|l|}{ B. fragilis } \\
\hline V479-1 & Contains $\mathrm{pBF} 4$ and chromosomal $\mathrm{Tc}^{\mathrm{r}}$ & - & $\begin{array}{c}\mathrm{Cc}^{\mathrm{r}} \mathrm{pBF} 4 \\
\text { Chromosomal } \mathrm{Tc}^{\mathrm{r}}\end{array}$ & Smith et al. (1982) \\
\hline V844 & Plasmidless & - & $\mathrm{Rf}^{\mathrm{r}}$ & Privitera et al. (1979) \\
\hline V1911 & Isogenic to V844 & - & $\mathrm{Rf}^{\mathrm{r}}, \mathrm{Fs}^{\mathrm{r}}$ & $\begin{array}{l}\text { C. J. Smith, East Carolina University, } \\
\text { USA }\end{array}$ \\
\hline \multicolumn{5}{|l|}{ E. coli } \\
\hline $\mathrm{DH} 5 \alpha$ & $\begin{array}{l}\mathrm{F}^{-}, \text {lacZ } \mathrm{ZM} 15 \Delta(\text { lacZYA-argF }) \mathrm{U} 169 \\
\left.\text { deoR recA1 endA1 hsdR17( } \mathrm{r}_{\mathrm{k}}^{-} \mathrm{m}_{\mathrm{k}}^{+}\right) \\
\text {supE44 } \lambda^{-} \text {thi-1 gyrA96 relA1 }\end{array}$ & $\mathrm{Nl}^{\mathrm{r}}$ & - & Gibco-BRL \\
\hline TB1 & $\begin{array}{l}\mathrm{F}^{-}, \text {ara }(\text { lac-proAB) rpsL d } \mathrm{d} l a c \Delta(\operatorname{lac} \mathrm{Z}) \\
\mathrm{M} 15 \text { hsdR }\left(\mathrm{r}_{\mathrm{k}}^{-} \mathrm{m}_{\mathrm{k}}^{+}\right)\end{array}$ & $\mathrm{St}^{\mathrm{r}}$ & - & Gibco-BRL \\
\hline M15 & $\mathrm{F}^{-}$, ara lac gal mtl & - & - & Qiagen \\
\hline \multicolumn{5}{|l|}{ Plasmids } \\
\hline pBF4 & Conjugative among Bacteroides spp. & - & $\mathrm{Cc}^{\mathrm{r}}$ & Welch \& Macrina (1981) \\
\hline pFD280 & oriT (E. coli) & $\mathrm{Sp}^{\mathrm{r}}$ & - & C. J. Smith \\
\hline pFD283 & B. fragilis-E. coli shuttle vector & $\mathrm{Sp}^{\mathrm{r}}$ & - & C. J. Smith \\
\hline pNFD13-2 & Contains cloned tet $Q$ & $\mathrm{Cb}^{\mathrm{r}}$ & $T c^{r}$ & $\begin{array}{l}\text { pBluescript derivative; A. A. Salyers, } \\
\text { University of Illinois, USA }\end{array}$ \\
\hline pQE-40 & Cloning vector for protein expression & $\mathrm{Cb}^{\mathrm{r}}$ & - & Qiagen \\
\hline pQE-41 & Cloning vector for protein expression & $\mathrm{Cb}^{\mathrm{r}}$ & - & Qiagen \\
\hline pREP4 & Contains lac repressor & $\mathrm{Kn}^{r}$ & - & Qiagen \\
\hline pVA829 & pBR322::pBF4 EcoRI-B & $\mathrm{Cb}^{\mathrm{r}}, \mathrm{Tc}^{\mathrm{r}}$ & - & $\begin{array}{l}\text { Unable to replicate in B. fragilis; } \\
\text { Mays et al. (1982) }\end{array}$ \\
\hline pVA831 & pBR322::pBF4 EcoRI-D & $\mathrm{Cb}^{\mathrm{r}}, \mathrm{Tc}^{\mathrm{r}}$ & - & $\begin{array}{l}\text { Unable to replicate in B. fragilis; } \\
\text { Mays } \text { et al. (1982) }\end{array}$ \\
\hline pVA832 & pBR325::pBF4 EcoRI-C & $\mathrm{Cb}^{\mathrm{r}}, \mathrm{Tc}^{\mathrm{r}}$ & - & $\begin{array}{l}\text { Unable to replicate in B. fragilis; } \\
\text { Mays et al. (1982) }\end{array}$ \\
\hline pVA833 & pBR322::pBF4 EcoRI-A & $\mathrm{Cb}^{\mathrm{r}}, \mathrm{Tc}^{\mathrm{r}}$ & - & $\begin{array}{l}\text { Unable to replicate in B. fragilis; } \\
\text { Mays et al. (1982) }\end{array}$ \\
\hline pVA835 & pBR322::pBF4 EcoRI-E & $\mathrm{Cb}^{\mathrm{r}}, \mathrm{Tc}^{\mathrm{r}}$ & $\mathrm{Cc}^{\mathrm{r}}$ & $\begin{array}{l}\text { Unable to replicate in } B \text {. fragilis; } \\
\text { Mays et al. (1982) }\end{array}$ \\
\hline pVA2122 & pFD283::tetQ & $S p^{r}$ & $\mathrm{Tc}^{\mathrm{r}}$ & This study \\
\hline pVA2165 & pUC19::pBF4 EcoRI-F & $\mathrm{Cb}^{\mathrm{r}}$ & $\mathrm{Tc}^{\mathrm{r}}$ & $\begin{array}{l}\text { Unable to replicate in } B \text {. fragilis; this } \\
\text { study }\end{array}$ \\
\hline pVA2200 & pFD280::tetQ & $\mathrm{Sp}^{\mathrm{r}}$ & $\mathrm{Tc}^{\mathrm{r}}$ & $\begin{array}{l}\text { Unable to replicate in } B \text {. fragilis; this } \\
\text { study }\end{array}$ \\
\hline pVA2201 & $\begin{array}{l}\mathrm{pVA} 2200:: 700 \mathrm{bp} E c o \mathrm{RI}-X b a \mathrm{I} \\
\text { fragment from pBF4 }\end{array}$ & $\mathrm{Sp}^{\mathrm{r}}$ & $\mathrm{Tc}^{\mathrm{r}}$ & $\begin{array}{l}\text { Unable to replicate in } B \text {. fragilis; this } \\
\text { study }\end{array}$ \\
\hline pVA2272 & $\begin{array}{l}\text { pVA2200::2.5 kb HindIII fragment } \\
\text { from pBF4 }\end{array}$ & $\mathrm{Sp}^{\mathrm{r}}$ & $\mathrm{Tc}^{\mathrm{r}}$ & $\begin{array}{l}\text { Unable to replicate in } B \text {. fragilis; this } \\
\text { study }\end{array}$ \\
\hline pVA2316 & $\begin{array}{l}\mathrm{pVA} 2200:: 1.9 \mathrm{~kb} \text { HindIII fragment } \\
\text { from pBF4 }\end{array}$ & $\mathrm{Sp}^{\mathrm{r}}$ & $\mathrm{Tc}^{\mathrm{r}}$ & This study \\
\hline pVA2318 & $\begin{array}{l}\text { pVA2200::900 bp internal ermF PCR } \\
\text { sequence }\end{array}$ & $\mathrm{Sp}^{\mathrm{r}}$ & $\mathrm{Tc}^{\mathrm{r}}$ & $\begin{array}{l}\text { Unable to replicate in } B \text {. fragilis; this } \\
\text { study }\end{array}$ \\
\hline pVA2320 & $\begin{array}{l}\text { pUC19:: } 12 \mathrm{~kb} \text { EcoRI-PstI fragment } \\
\text { from pBF4 }\end{array}$ & $\mathrm{Cb}^{\mathrm{r}}$ & - & $\begin{array}{l}\text { Unable to replicate in B. fragilis; this } \\
\text { study }\end{array}$ \\
\hline RK231 & Mobilizing vector & $\mathrm{Tc}^{\mathrm{r}}, \mathrm{Kn}^{\mathrm{r}}$ & - & Guiney et al. (1984) \\
\hline R751::Tn4351 24 & $\begin{array}{l}\text { Suicide vector to introduce } \mathrm{Tn} 4351 \text { into } \\
\text { Bacteroides }\end{array}$ & $T \mathrm{p}^{\mathrm{r}}$ & $\mathrm{Cc}^{\mathrm{r}}($ from $\mathrm{Tn} 4351)$ & Shoemaker et al. (1986) \\
\hline
\end{tabular}

*Abbreviations used for antibiotic resistance $(r)$ or sensitivity $(s)$ in the respective organism: $\mathrm{Cb}$, carbenicillin; $\mathrm{Cc}$, clindamycin; $\mathrm{Fs}$, fusidic acid; Kn, kanamycin; Rf, rifampicin; Sp, spectinomycin; St, streptomycin; Tc, tetracycline; Tp, trimethoprim. 
Macrina, 1981) and pBI136 (82 kb) (Smith, 1985). There are no reports describing pili-like surface structures of Bacteroides spp. involved in the conjugal process. Another noteworthy difference as compared to $E$. coli conjugation is that DNA transfer does not occur when cells are suspended in an aqueous environment. Bacteroides spp. mating mixtures must be collected on a solid (nitrocellulose or polycarbonate filter) or semisolid (agar) surface for plasmid transfer to take place.

Hecht et al. (1991) identified a region conferring conjugal transfer ability on pBFTM10 and described two genes, $b \operatorname{tg} A$ and $b \operatorname{tg} B$, required for Bacteroides spp. conjugal transfer. These genes were needed for pBFTM10 to be mobilized by the IncP $\beta$ plasmid $\mathrm{R} 751$ in $E$. coli matings. Further, these workers identified a sequence resembling an oriT-like region seen on plasmids of Gram-negative origin. Novicki \& Hecht (1995) have recently studied a recombinant plasmid consisting of a $4.2 \mathrm{~kb}$ Bacteroides spp. plasmid (pVL22a) fused to a Bacteroides-E. coli shuttle. Mutagenesis studies and nucleotide sequence analysis revealed that three pLV22a genes, $m b p A, B$ and $C$, were essential for plasmid mobilization mediated by plasmid R751 in E. coli matings. A cis-acting region, possibly an oriT sequence, was demonstrated within $m b p A$.

We have studied the genetic basis of pBF4-mediated conjugal transfer. Here, using a recombinational mutagenesis system, we have isolated a conjugation-deficient derivative of pBF4. We have characterized this mutant and determined the sequence of a new gene, $b c t A$, which is necessary for conjugal transfer.

\section{METHODS}

Bacterial strains and growth. The bacterial strains and plasmids used in this study are described in Table 1. Bacteroides fragilis strains were maintained on brain heart infusion (BHI; Difco Laboratories) broth supplemented with $\left(l^{-1}\right)$ : DL-cysteine, $1.0 \mathrm{~g}$; haemin, $5.0 \mathrm{mg}$; menadione, $1.0 \mathrm{mg}$; agar (when required), $20 \cdot 0 \mathrm{~g}$. Bacteroides spp. were grown in an anaerobic chamber (Coy Laboratory Products) containing an atmosphere of $80 \% \mathrm{~N}_{2}, 10 \% \mathrm{CO}_{2}$ and $10 \% \mathrm{H}_{2}$. E. coli strains were grown aerobically in Luria broth (LB; Gibco$\mathrm{BRL})$. Agar was added $(2 \%, \mathrm{w} / \mathrm{v})$ when solid medium was required. All cultures were incubated at $37^{\circ} \mathrm{C}$. The following antibiotic concentrations $\left(\mu \mathrm{g} \mathrm{ml}^{-1}\right)$ were used to select $B$. fragilis strains: clindamycin (Cln), 5.0; fusidic acid (Fus), 20; rifampicin (Rif), 20; tetracycline (Tet), 7.5. The following antibiotic concentrations $\left(\mu \mathrm{g} \mathrm{m}^{-1}\right)$ were used to select $E$. coli strains: carbenicillin (Car), 50; geneticin (Gen), 200; nalidixic acid $(\mathrm{Nal}) 30$; spectinomycin (Spc), 50; Tet, 10 . All antibiotics were obtained from Sigma. X-Gal was added to a final concentration of $10 \mathrm{\mu g} \mathrm{ml}^{-1}$ to detect $\beta$-galactosidase production.

Preparation and analysis of DNA. Plasmid DNA extractions were performed by alkaline lysis as described by Birnboim $\&$ Doly (1979), using $10 \mathrm{ml}$ overnight cultures of $B$. fragilis strains. Large-scale preparations of plasmid DNA were isolated by caesium chloride/ethidium bromide equilibrium ultracentrifugation (Sambrook et al., 1989) or by using a
Qiagen column. DNA was digested with restriction enzymes as specified by the manufacturer (Gibco-BRL) and analysed by gel electrophoresis $[0.8 \%$ agarose; TAE buffer $(0.04 \mathrm{M}$ Tris/ acetate, $0.001 \mathrm{M}$ EDTA, $\mathrm{pH} 8.0$ )]. DNA fragments were excised from the agarose gels and purified using the GeneClean system (Bio101). DNA labelling and autoradiography were done as previously reported (Macrina et al., 1981). Electroporation was used to introduce various plasmid constructs into E. coli as described by Dower et al. (1988).

Plasmid construction. pVA2122, a novel B. fragilis-E. coli shuttle vector, was constructed by ligating the $2.6 \mathrm{~kb} \mathrm{SacI}$ fragment of pNFD13-2 containing the entire tet $Q$ gene into the SacI site of pFD283. pVA2200 was constructed by treating the $2.6 \mathrm{~kb} \mathrm{SacI}$ fragment of pNFD13-2 containing the tet $Q$ gene with Klenow fragment, which created a blunt-ended molecule, and ligating it into the NdeI site of pFD280, which was also treated with Klenow fragment (Fig. 1).

To determine if recombination between pBF4 and pVA2200derivatives would occur, a control vector was created. pVA2318 contained a subcistronic region of ermF cloned into pVA2200. The ermF region was large enough to promote homologous recombination between pVA2318 and pBF4. To create pVA2318, two oligonucleotide primers were used to amplify by PCR an internal DNA fragment of ermF with subsequent cloning into the multiple-cloning site (MCS) of pVA2200. The two primers were purchased from Oligos Etc. The left primer was $5^{\prime}$ GCCGCTTCGTTTTACGGGTCAGC-3' and the right primer was 5'-GGAGACAAACAAACAATTTGAGC-3'. PCR amplification was performed in a Perkin Elmer Cetus DNA Thermal Cycler as described by Sambrook et al. (1989). The reaction mixture contained $700 \mathrm{ng}$ each primer, $70 \mathrm{ng}$ pVA834, and $1 \mu \mathrm{l}$ Vent Polymerase (New England Biolabs). The PCR reaction consisted of 28 cycles with a temperature profile of $1 \mathrm{~min}$ at $94^{\circ} \mathrm{C}, 2 \mathrm{~min}$ at $48^{\circ} \mathrm{C}$, and $3 \mathrm{~min}$ at $72^{\circ} \mathrm{C}$. The resulting $900 \mathrm{bp}$ fragment was extracted from an agarose gel and was ligated into the SmaI site of pVA2200. E. coli transformants were selected on LB agar containing Spc and XGal. pVA2201, pVA2272, pVA2316 and pVA2325 were all created by cloning various restriction enzyme fragments of pBF4 into the MCS of pVA2200 (Table 1).

To verify that the integration of pVA2200 sequences downstream of $b c t A$ did not inhibit the conjugation of $\mathrm{pBF} 4$, pVA2326 was constructed. A 900 bp PCR fragment, which was downstream of $b c t A$, was ligated into pVA2200. The left primer was 5'-CCGGCTTTATTATTGGTGTCAGC-3' and the right primer was 5'-GCTGCTAATGCCTGTGCATCTGC- $3^{\prime}$. The reaction mixture contained $700 \mathrm{ng}$ each primer, 70 ng pVA2320 (template DNA), and $1 \mu$ l Vent polymerase (New England Biolabs). The PCR reaction consisted of 28 cycles with a temperature profile of $1 \mathrm{~min}$ at $94^{\circ} \mathrm{C}, 2 \mathrm{~min}$ at $50^{\circ} \mathrm{C}$, and $3 \mathrm{~min}$ at $72^{\circ} \mathrm{C}$. Transformants were selected and verified as described for the other pVA2200-derivatives.

Bacterial conjugation. For the transfer of plasmids from $E$. coli donors to $E$. coli recipients, standard filter matings were used (Shoemaker et al., 1986). RK231 was used in matings involving the transfer of plasmids from $E$. coli donors to $B$. fragilis recipients, as well as screening for the presence of an oriT. Standard filter-mating techniques were performed with the following modifications (Shoemaker et al., 1986). Earlyexponential-phase $E$. coli and $B$. fragilis cells were concentrated by centrifugation and placed on nitrocellulose filters (donor to recipient ratio of $20: 1$ ). The filters were incubated 
on BHI agar aerobically for $16 \mathrm{~h}$. The filters were removed and placed in $1 \mathrm{ml} \mathrm{BHI}$, incubated under anaerobic conditions for $20 \mathrm{~h}$, and plated on selective media, which contained Gen and $\mathrm{Nal}$ (for selection against $E$. coli).

Plasmid matings between $B$. fragilis strains were performed using early exponential phase cells as described above with a $1: 1$ donor to recipient ratio $(20 \mu$ l total mating mixture). Mating mixtures were incubated anaerobically for $6 \mathrm{~h}$. Transfer frequencies are reported as the number of transconjugants per input donor cell.

Nucleotide sequence analysis. Nucleotide sequence analysis was performed by automated sequencing using a Taq DyeDeoxy Terminator Cycle Sequencing kit as described by the manufacturer (ABI). Each reaction contained $2 \mu \mathrm{g}$ template DNA and $3.2 \mathrm{pmol}$ primer. Removal of unincorporated nucleotides and proteins was carried out with Centri-sep columns (Centri-sep). The samples were freeze dried and analysed by the VCU Nucleic Acid Core Facility Laboratory. Three subclones, a $1.9 \mathrm{~kb}$ HindIII fragment (pVA2316), a $1.0 \mathrm{~kb}$ NruI-HindlII fragment (pVA2325), and a 3.5 NruI-PstI fragment (pVA2323) of pVA2320 were independently ligated into the MCS of pUC19 or pVA2200 and initially used as template DNA. Standard M13 forward and reverse oligonucleotide primers were used to begin sequencing of the corresponding DNA strands. Primer-walking using pVA2320 as template was performed to link the three subclones. The various sequences were aligned with AssemblyLIGN (IBI MacVector) software package (Eastman Kodak) to create sequence overlaps. The University of Wisconsin GCG DNA sequence analysis software and MacVector were used for computer analysis of DNA and protein sequences.

Isolation of proteins from $B$. fragilis. Cell-free extracts were prepared from 11 overnight cultures as previously described (Salyers \& O'Brien, 1980). The supernatants were pooled and centrifuged at $140000 \mathrm{~g}$ for $2 \mathrm{~h}$ to separate the membraneassociated fraction of proteins from the soluble fraction (Salyers \& O'Brien, 1980). The membrane pellet was suspended in $15 \mathrm{ml}$ PBS $\left(0 \cdot 14 \mathrm{M} \mathrm{NaCl}, 0 \cdot 1 \mathrm{M} \mathrm{Na}_{2} \mathrm{HPO}_{4}, 0 \cdot 1 \mathrm{M}\right.$ $\mathrm{KH}_{2} \mathrm{PO}_{4}, \mathrm{pH} 7 \cdot 3$ ).

Proteins were suspended in running dye, $(0.05 \mathrm{M}$ Tris, $\mathrm{pH} 6.8$; SDS, $2 \% \mathrm{w} / \mathrm{v}$; bromophenol blue, $0 \cdot 1 \% \mathrm{w} / \mathrm{v}$; glycerol, $10 \%$ $\mathrm{v} / \mathrm{v}$; and $\beta$-mercaptoethanol, $5 \% \mathrm{v} / \mathrm{v}$ ) incubated at $95^{\circ} \mathrm{C}$ for $5 \mathrm{~min}$, and separated by $10 \%$ PAGE in running buffer $(0.025 \mathrm{M}$ Tris and $0.192 \mathrm{M}$ glycine, $\mathrm{pH} 8.3)$ and stained with Coomassie Brilliant Blue (Sambrook et al., 1989).

In vitro expression of BctA. Two micrograms of $\mathrm{CsCl}$ densitygradient-purified pVA2320 was used as template DNA in the Promega E. coli S30 extract kit (Promega) using ${ }^{35} \mathrm{~S}-\mathrm{meth}$ ionine to label the proteins at $37^{\circ} \mathrm{C}$ as described by the manufacturer. The samples were analysed by electrophoresis on a $10 \%$ PAGE. The gel was dried and exposed to reflection autoradiography film (DuPont-NEN) for $3-20 \mathrm{~h}$ at $-70^{\circ} \mathrm{C}$.

Immunological identification of BctA. The Qiaexpress Vector kit (Qiagen) was used to generate plasmid constructs that expressed sub-sequence peptides of BctA. The first was a 107 amino acid (aa) polypeptide (BctA.1) beginning at aa 789 and the second was a 187 aa polypeptide (BctA.2) beginning at aa 468. Primers were designed and used to amplify the DNA regions by PCR. The primers were designed to have either a BglII or PstI restriction site incorporated into the sequence. The presence of these restriction sites allowed for the ligation of the amplified DNA fragments into the appropriate $\mathrm{pQE}$ vector ( $\mathrm{PQE} 40$ for the 187 aa polypeptide, $\mathrm{PQE} 41$ for the
107 aa polypeptide). The primers for BctA.1 were: left, $5^{\prime}$ CTCAGATCTTATATGCCTATTAGACC-3' ; right, $5^{\prime}$ GGAAGCCTGCAGGTCTATTATAAAATTATC- $3^{\prime}$. The primers for BctA.2 were: left, 5'-GCCAAGATCTATGAATCCTTTCCG-3' ; right, 5'-GTTCTCTCTGCAGATGATAGGTATAATG-3'. The Pst I sites embedded in both of the right primers and the $B g l \mathrm{II}$ sites embedded in both of the left primers are shown in bold.

The reaction mixture contained $70 \mathrm{ng}$ template DNA (pVA2320), $700 \mathrm{ng}$ of each primer, and $1 \mu \mathrm{l}$ Vent Polymerase (New England BioLabs). The PCR reaction consisted of 28 cycles with a temperature profile of $1 \mathrm{~min}$ at $94^{\circ} \mathrm{C}, 2 \mathrm{~min}$ at $48^{\circ} \mathrm{C}$, and $3 \mathrm{~min}$ at $72^{\circ} \mathrm{C}$. The resulting PCR products, $324 \mathrm{bp}$ for BctA.1 and $564 \mathrm{bp}$ for BctA.2, were purified from TAE agarose gels, ligated into the appropriate $\mathrm{pQE}$ vector, and electroporated into $E$. coli M15 containing the regulatory plasmid pREP4 (Qiagen). Transformants were selected on LB agar plates containing Car and Kan. Transformants were verified by nucleotide sequence analysis and examination of the plasmid DNA on agarose gels.

Expression and purification of the polypeptide was performed as specified by the manufacturer (Qiagen). Pooled fractions of the protein were dialysed overnight against $1 \times$ PBS. The resulting precipitated protein was briefly sonicated to disrupt aggregates.

Sterile PBS $(0.5 \mathrm{ml})$ containing $0.75 \mathrm{mg}$ each purified protein was mixed with $0.5 \mathrm{ml}$ complete Freund's adjuvant (Sigma) and injected subcutaneously into $4.0 \mathrm{~kg}$ New Zealand white female rabbits. The rabbits received a second subcutaneous injection containing $0.5 \mathrm{mg}$ protein mixed with $0.5 \mathrm{ml}$ incomplete Freund's adjuvant after 4 weeks. To test for the presence of antibodies to each of the polypeptides, $10 \mathrm{ml}$ blood from each rabbit was obtained 2 weeks later. Rabbit antisera were prepared under an authorized Virginia Commonwealth University, Institutional Use and Care of Animals Committee protocol.

Total, soluble, and membrane fractions from various $B$. fragilis strains were separated on $10 \%$ polyacrylamide gels and electrotransferred to reinforced nitrocellulose $(0.45 \mu \mathrm{m}$ pore size; Schleicher $\&$ Schuell) using a MiniTransBlot cell unit from Bio-Rad in transfer buffer (0.025 M Tris, 0.192 M glycine, $20 \%$ methanol, $\mathrm{pH} 8.3$ ) at $100 \mathrm{~V}$ for $1 \mathrm{~h}$. The nitrocellulose membrane then was used in Western blot analysis utilizing horseradish peroxidase linked to anti-rabbit IgG as described by the manufacturer (Promega). A 1:100 to 1:500 dilution of serum containing the antibodies to BctA.1 or BctA. 2 was used in the assay.

Fluorescence microscopy. A $1 \mathrm{ml}$ overnight culture of either V844, V844 containing pBF4, or V844 containing pBF4::pVA2316 were centrifuged and suspended in $0.1 \mathrm{ml}$ PBS. Twenty microlitres of the cells were incubated with $20 \mu \mathrm{l}$ of a 1:100 dilution of BctA.2 in the dark for $30 \mathrm{~min}$. The cells then were washed with $500 \mu$ PBS in the dark for $30 \mathrm{~min}$. The cells were pelleted by brief centrifugation followed by removal of the supernate. The cells then were incubated in the dark with $20 \mu \mathrm{l}$ of a $1: 100$ dilution of a $1.5 \mathrm{mg} \mathrm{ml}^{-1}$ stock of fluorescein-conjugated goat anti-rabbit IgG (Jackson Immunoresearch) for $30 \mathrm{~min}$. The cells were suspended in $500 \mu \mathrm{l}$ PBS for $30 \mathrm{~min}$ and pelleted. The cells were then suspended in $20 \mu \mathrm{l}$ PBS and one drop was placed on a microscope slide containing a drop of Mowiol 4-88 (CalBiochem) containing 1,4diazobicyclo-[2,2,2]-octane $\left(10 \mu \mathrm{g} \mathrm{ml}^{-1}\right.$; Sigma) to prevent photobleaching. After the addition of a cover slip, the slides were examined using an Olympus model Bx-50 fluorescence microscope. 


\section{RESULTS}

\section{Development of a system to mutagenize pBF4}

To isolate conjugation-deficient mutants of pBF4, we initially tried transposon mutagenesis using a Tn4351based delivery system (Rasmussen et al., 1987; Shoemaker et al., 1986). We isolated numerous transposon mutants using this system, but found that integration of the transposon occurred at the same region on the pBF4deletion derivative, owing to homologous recombination between IS4351 sequences on both the transposon and pBF4. These results indicated that the use of Tn4351 would not provide a random set of insertion mutants and this necessitated the development of an alternative mutagenesis system.

We created a plasmid construct that would allow us to do insertion-duplication mutagenesis in Bacteroides spp. The elements of this mutagenesis system were: (1) a suicide vector unable to replicate in Bacteroides spp., (2) a directly selectable marker, tetracycline resistance (tet $Q$ ), and (3) convenient restriction endonuclease sites into which DNA could be inserted. The construction of this plasmid, pVA2200, is illustrated in Fig. 1.

To first test this system, we created a subcistronic fragment of the ermF gene by PCR using appropriate oligonucleotide primers (see Methods). This $900 \mathrm{bp}$ fragment was ligated into pVA2200 to form pVA2318. pVA2318 was mobilized by RK231 from $E$. coli into $B$. fragilis V844 containing native $\mathrm{pBF} 4$. The results showed that the predicted integration event occurred between pVA2318 and pBF4 and that these co-integrates were clindamycin sensitive, indicating inactivation of ermF (Fig. 2). The co-integration of pVA2318 into pBF4 was also verified by Southern blot analysis of EcoRI-digested co-integrate plasmid DNA using the entire pVA2218 plasmid as a probe (data not shown). The resulting pBF4::pVA2318 co-integrate transferred at wild-type frequencies when compared to pBF4 (Table 2 , rows 2 and 3).

We proceeded to isolate insertion-duplication mutants of pBF4 using this system. Four different restriction fragments initially were cloned into pVA2200: a $700 \mathrm{bp}$ $E c o$ RI-XbaI fragment from the EcoRI-E fragment (pVA2201), a $2.5 \mathrm{~kb}$ HindIII fragment from the EcoRI-C fragment (pVA2272), a $1.9 \mathrm{~kb}$ HindIII fragment from the EcoRI-A fragment (pVA2316), and a $1 \cdot 1 \mathrm{~kb}$ NruI-HindIII fragment from the EcoRI-A fragment (pVA2325) (see Fig. 3). In subsequent experiments, a fifth fragment consisting of a 912 bp PCR-amplified region of pBF4 that was approximately 500 bp downstream of an ORF (pVA2326) was also cloned into pVA2200 and investigated (see below). All of the pVA2200 clones integrated predictably into pBF4 as judged by Southern blot analysis of restriction-enzymecleaved fragments (data not shown). The relative position of each co-integrate in pBF4 is presented in Fig. 3. Each of the pBF4::pVA2200-derivative co-integrates were examined to determine if they would transfer to $B$. fragilis V1911. The results of the mating experiments using the co-integrates are seen in Table 2. The only pBF4 plasmid containing an insert that did not exhibit wild-type conjugative transfer frequency was pVA2316 (Table 2, line 5; also see Fig. 3). The other co-integrate plasmids containing specific inserts all transferred at frequencies within one order of magnitude of wild-type pBF4 (Table 2).

\section{Nucleotide sequence analysis}

Based on the above results, we concluded that pVA2316 inserted into $\mathrm{pBF} 4$, inactivating one or more genes governing conjugal transfer ability. To evaluate the region marked by the pVA2316 insertion, the nucleotide sequence of this area of pBF4 was determined. A large ORF of 2838 bp encoding a putative protein of 946 aa was discovered by this analysis (Fig. 3). Based on the size of the region carried by pVA2316 and nucleotide sequence information, its integration into pBF4 was restricted to some area within the 946 aa ORF (Fig. 3). Thus, the pVA2316 insert inactivated this ORF. The pVA2325 and pVA2326 inserts occurred outside of the ORF, indicating that insertion into these areas did not interrupt expression of the 946 aa ORF (Fig. 3). Both of these pBF4 insertion derivatives (pBF4::pVA2325 and pBF4::pVA2326) were conjugative at wild-type frequencies (Table 2, rows 6 and 7).

Neither the DNA sequence of the $2 \cdot 8 \mathrm{~kb}$ ORF nor its deduced amino acid sequence displayed similarity to sequences in the GenBank, EMBL or SWISS-PROT databases (GCG) or to sequences in the BLOCKs e-mail searcher database. In fact, when the entire 7786 bp DNA sequence was subjected to a database search using GenBank, we found no similarities to known nucleotide or aa sequences. We concluded that the gene encoded by the $2.8 \mathrm{~kb}$ ORF was involved in conjugal transfer and designated it $b c t A$ ( $\underline{B}$ acteroides conjugal transfer).

We also examined the entire $\mathrm{pBF} 4$ nucleotide sequence for an oriT based on a comparison to conserved oriT domains (Lanka \& Wilkins, 1995). No sequence homology to oriT consensus sites was found in this region. Preliminary attempts to identify a functional oriT site were unsuccessful (data not shown). We cloned various restriction fragments representing all of $\mathrm{pBF} 4$ into a non-mobilizable plasmid. We then attempted to mobilize these constructs using RK231, but transfer was never achieved with any of these plasmids.

\section{Characterization of bctA}

The $b c t A$ gene encoded a putative $110 \mathrm{kDa}$ protein with a predicted pI of $5 \cdot 49$. To test the expression of $b c t A$, pVA2320 was employed as the template in an in vitro transcription-translation system using $E$. coli $\mathrm{S} 30$ extracts. The results indicated that a $110 \mathrm{kDa}$ protein was made in the in vitro system (Fig. 4), consistent with the predicted size of the $b c t A$ gene product. Three other proteins, ranging in size from $24-48 \mathrm{kDa}$, also were produced in this system (Fig. 4). These smaller proteins 

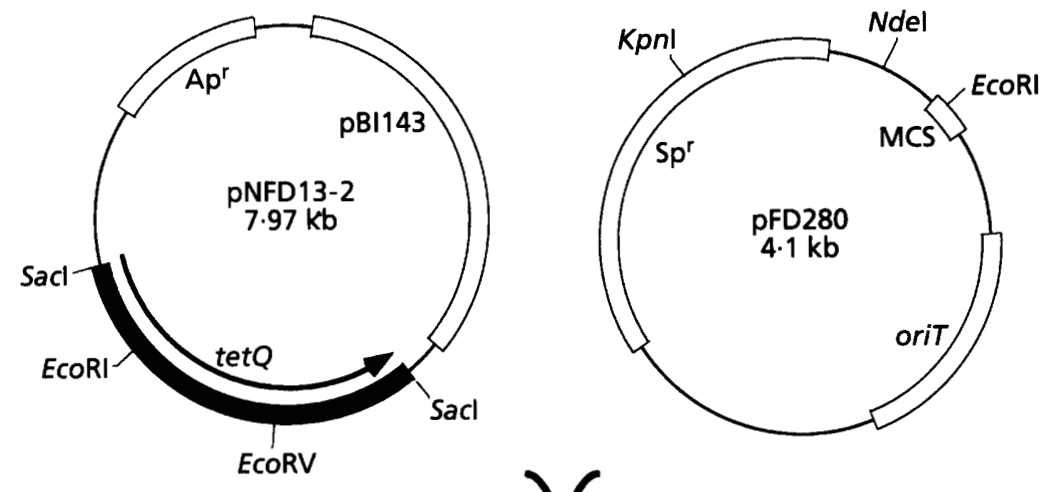

$\gamma$

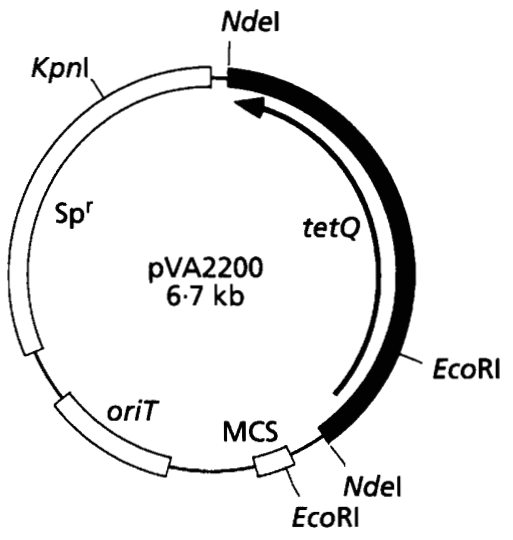

Fig. 1. Construction of pVA2200. pNFD13-2 was digested with $\mathrm{SaCl}$ and the $2.5 \mathrm{~kb}$ fragment containing tetQ was purified and treated with Klenow fragment to create blunt ends. tetQ confers Tet resistance in $B$. fragilis and low-level Tet resistance in E. coli. pFD280 was digested with Ndel and also treated with Klenow fragment to form a blunt-ended molecule. The tet $Q$ fragment was ligated to the $N$ del-cleaved pFD280 and transformants were selected in $E$. coli for resistance to Spc and Tet. pFD280 contained the $\mathrm{Sp}^{r}$ determinant from $\mathrm{pDL} 278$, a small segment of the pUC19 region containing the multiple-cloning site (MCS) and the origin of transfer from RK2 (oriT). Arrows indicate the transcription directions of the respective genes. may be encoded on the $12 \mathrm{~kb}$ pBF 4 insert, or they may be degradation products of the $110 \mathrm{kDa}$ species. DNA sequence analysis of the upstream region of $b c t A \operatorname{did}$ not result in any sequences that would indicate a transcriptional regulatory region, such as a TATA box or a -35 region commonly associated with prokaryotic genes. A cognate E. coli or B. fragilis Shine-Dalgarno sequence was also lacking. Analysis of the downstream region of $b c t A$ did not reveal any sequences that may be involved in rho-dependent or rho-independent termination.

\section{The dissemination of bctA}

A $b c t A$ probe was used to evaluate the presence of this gene in other conjugal donors. Previous studies identified 13 different Bacteroides spp. clinical isolates that were resistant to Tet, Cln or both drugs; nine of these isolates contained plasmids of various sizes, ranging from $2 \cdot 1$ to $38.0 \mathrm{~kb}$ (Fletcher \& Macrina, 1991). Four of the clinical isolates were able to transfer their antibiotic resistance by conjugation, indicating the presence of some type of conjugation system. All 13 isolates, B. fragilis V844 and Bacteroides uniformis V528 (both of which may contain a cryptic Bacteroides spp. conjugal element, but lack plasmid DNA), and B. fragilis V503 (a strain known to contain a Bacteroides spp. conjugative transposon) were tested for hybridization to the $1.9 \mathrm{~kb}$ HindIII fragment (internal to the $b c t A$ ORF) used to make pVA2316.
Southern hybridizations using $40 \%$ stringency conditions were performed on intact DNA as well as HindIII-digested DNA fragments from the various strains. The probe did not hybridize with plasmid or chromosomal DNA from any of the tested strains (data not shown).

\section{Construction and expression of BctA sub-sequence polypeptides}

To gain a better understanding of the role $\mathrm{Bct} A$ has in the conjugative transfer of $\mathrm{pBF} 4$, purification of $\mathrm{BctA}$ and sub-sequence polypeptides of the protein was performed. The Qiaexpress system was used for the over-expression of the BctA protein and sub-sequence polypeptides. This system allowed for the cloning of the DNA encoding the protein of interest downstream from a hexahistidine-encoding region. The entire $b c t A$ coding region was amplified by PCR and ligated into a Qiaexpress vector. The expression of the protein, however, was not observed. To increase the chances of expression of a protein in the system, sub-sequence polypeptides were used. Antigenicity and hydrophilicity plots were analysed to locate regions predicted to elicit good immunological responses. Two antigenic regions of BctA were used, BctA.1 and BctA.2 (Fig. 3). The two regions of DNA corresponding to these sub-sequence polypeptides were amplified by PCR and individually ligated into a Qiaexpress vector. BctA.1 was cloned into 
(a)

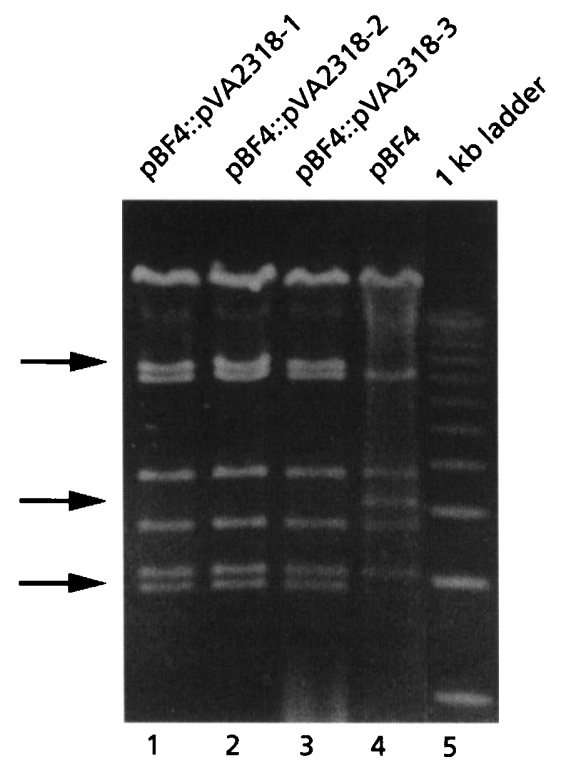

(b)
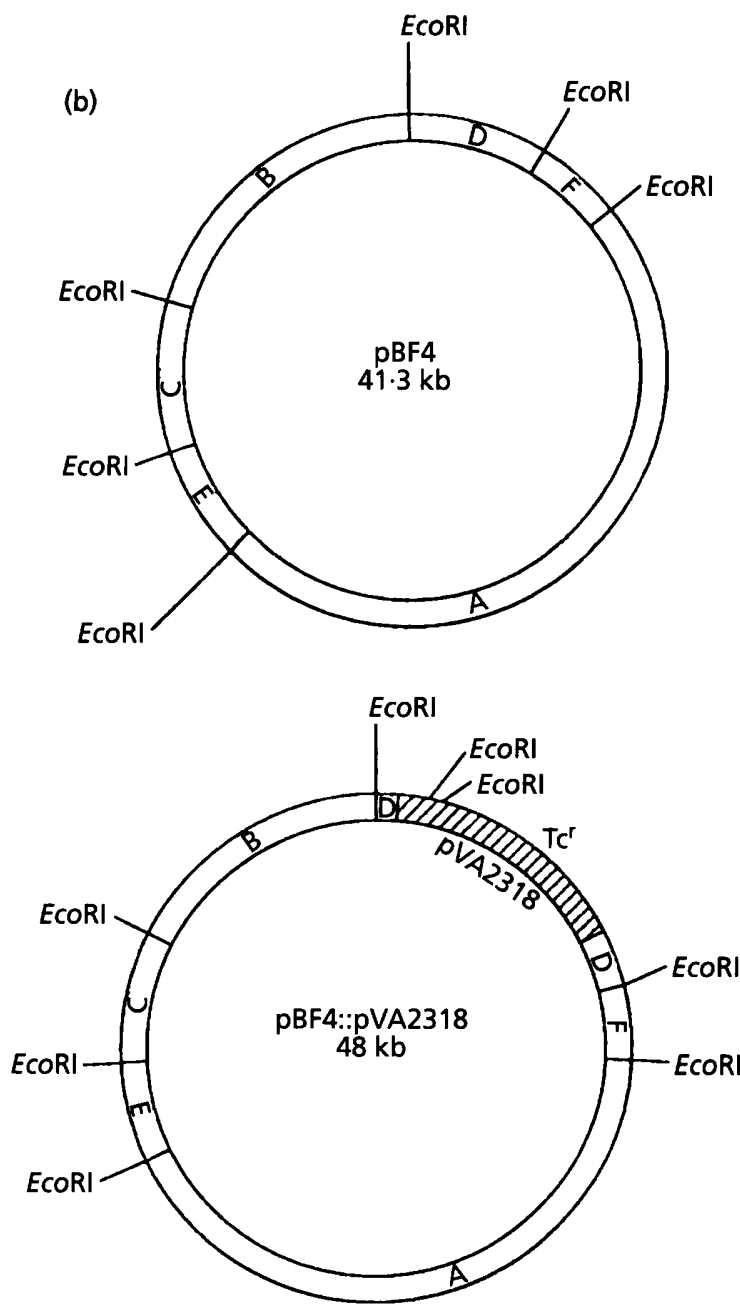

Fig. 2. Co-integrate formation between pVA2318 and pBF4. (a) Ethidium-bromide-stained agarose gel displaying the EcoRI digests of three independent co-integrates from $B$. fragilis (lanes 1-3) and pBF4 (lane 4). Lane 5 contains a $1 \mathrm{~kb}$ lambda DNA ladder. The top and bottom arrows represent the two additional EcoRI fragments predicted to arise from the
pQE41 and BctA.2 was cloned into pQE40. The subsequent nucleotide sequence of the clones were determined to ensure that the fused sequences were in the appropriate coding frame. The expression of the predicted sizes of both polypeptides was observed (data not shown). In this system each of the sub-sequence peptides were produced as fusion proteins linked to the C-terminus of dihydrofolate reductase (DHFR). The DHFR::BctA.1 protein was $33 \mathrm{kDa}$ and the BctA.2::DHFR protein was $45 \mathrm{kDa}$.

\section{Immunological analysis of BctA}

The BctA.1 and BctA.2 fusion proteins were each used to immunize rabbits. Each fusion protein elicited a specific antibody response from the injected rabbits and reactivity was detected using Western blot analysis (data not shown). Antiserum dilutions greater than 1:500 failed to detect proteins in Western blot analysis (data not shown). Total cellular extracts from $B$. fragilis $\mathrm{V} 844, B$. fragilis $\mathrm{V} 844$ containing $\mathrm{pBF} 4$, or $B$. fragilis V844 containing pBF4::pVA2316 were used to determine by Western blot analysis if the rabbit antibodies recognized any protein(s). The antibodies to BctA.1 did not recognize any $B$. fragilis proteins from any of the strains (data not shown); however, antibodies to BctA.2 did recognize a $55 \mathrm{kDa}$ protein that was present in $B$. fragilis containing native pBF4 (Fig. 5, lane D) but they did not recognize proteins from an isogenic strain missing pBF4 (Fig. 5, lane B) or one containing pBF4::pVA2316 (Fig. 5, lane C). Furthermore, the $55 \mathrm{kDa}$ protein from $B$. fragilis V844 containing pBF4 was present in the membrane-associated fraction of the cells (Fig. 5, lane F). Antibodies to either sub-sequence polypeptide did not recognize proteins from E. coli containing pVA2320, indicating low expression of the protein or protein degradation (data not shown). The size of the immunoreactive protein was much smaller than the $110 \mathrm{kDa}$ predicted from the DNA sequence. In an attempt to eliminate the possibility of non-specific protease activity of native $\mathrm{Bct} A$, protein purification using various protease inhibitors was utilized. The protease inhibitors tested were $0.5 \mathrm{M} \mathrm{NaCl}, 1 \%$ SDS and $N \alpha$-p-tosyl-L-lysine chloromethyl ketone (TLCK); we also tried direct analysis of intact $B$. fragilis cells by lysis of the cells in the loading buffer. In all cases only the $55 \mathrm{kDa}$ protein was visualized in Western blot analysis (data not shown).

\section{Attempted localization of BctA}

The previous results indicated that the BctA protein was located in the membrane fraction of the cells and that interruption of the gene inhibited conjugation of pBF4.

integration process (see maps). The middle arrow indicates the corresponding position of the missing EcoRI-D fragment from pBF4 predicted from the integration process (see maps). The EcoRI-D fragment can be seen in lane 4 (pBF4). (b) EcoRI restriction endonuclease site map of pBF4 and pBF4::pVA2318. The ECORI restriction fragments are indicated by upper-case letters (A-F). 
Table 2. Conjugation frequency of six insertion mutants of pBF4 compared to wild-type pBF4

The donor was V844 containing the indicated plasmid and the recipient was V1911. Conjugation frequency is number of transconjugants per input donor cell.

\begin{tabular}{|lll|}
\hline Insert & \multicolumn{1}{c|}{ Description } & Conjugation frequency \\
\hline pBF4 & Wild-type & $1.3 \times 10^{-4}-4.7 \times 10^{-3}$ \\
pBF4::pVA2318 & Insertion into $e r m F$ gene (EcoRI-D fragment) & $2.4 \times 10^{-4}-3.6 \times 10^{-4}$ \\
pBF4::pVA2201 & Insert into EcoRI-E fragment & $6.2 \times 10^{-5}-1 \cdot 1 \times 10^{-4}$ \\
pBF4::pVA2272 & Insert into EcoRI-C fragment & $1.2 \times 10^{-5}-1.5 \times 10^{-4}$ \\
pBF4::pVA2316 & Insert into EcoRI-A fragment & $<1 \times 10^{-7}-<4.3 \times 10^{-7}$ \\
pBF4::pVA2325 & Insert into EcoRI-A fragment & $1.2 \times 10^{-4}-5.2 \times 10^{-4}$ \\
pBF4::pVA2326 & Insert into EcoRI-A fragment & $3.3 \times 10^{-4}-2.4 \times 10^{-3}$ \\
\hline
\end{tabular}

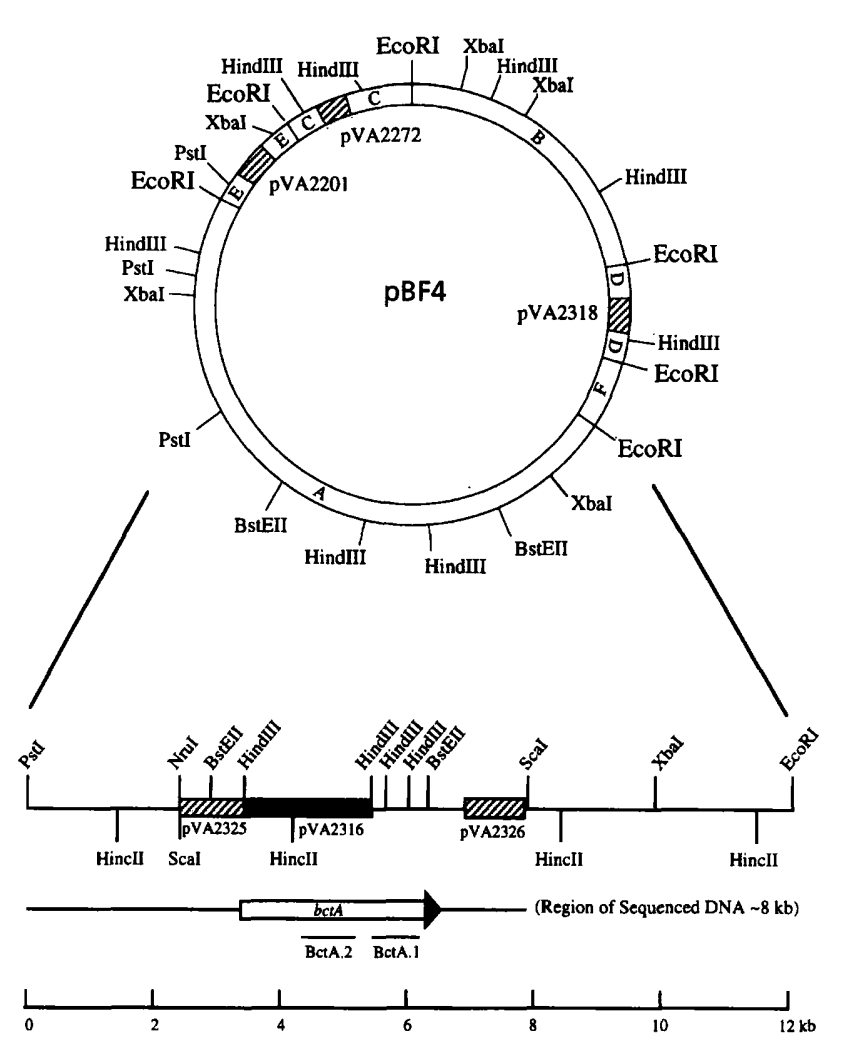

Fig. 3. Restriction endonuclease site map of pBF4. Each integration event occurred by insertion of a plasmid into pBF4 and the name of the integrating plasmid is given and the position is indicated by the hatched region. EcoRl fragments are indicated by the upper-case letters (A-F) on the circular map. The position and predicted direction of transcription of the bct $A$ gene is shown as the linear expanded map below the circular map. The three boxes on the linear map represent fragments of DNA that were used to create plasmids (pVA2325, pVA2316 and pVA2326) for co-integration into pBF4. The pVA2316 insertion into pBF4 was the only insertion mutant that inhibited the conjugative transfer of pBF4. BctA.1 and BctA.2 indicate two regions of BctA that were expressed as fusion proteins and purified in E. coli.

To determine if antibodies raised against BctA.2 would recognize BctA on the surface of whole cells, two experiments were performed.

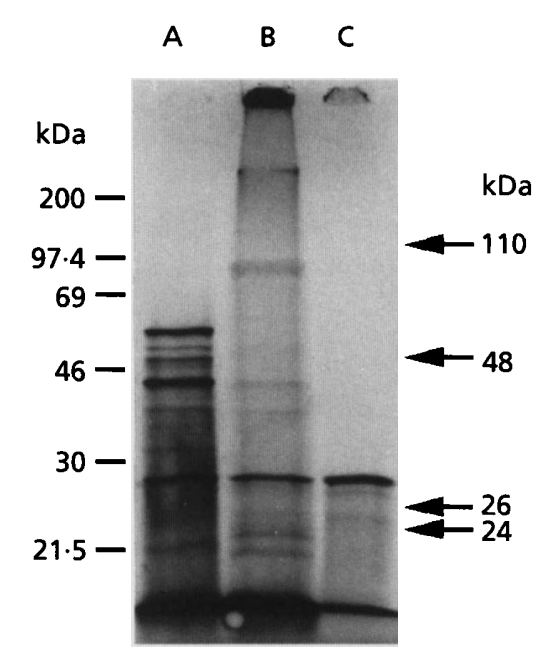

Fig. 4. In vitro expression of bctA. A Promega in vitro transcription-translation kit with ${ }^{35} \mathrm{~S}$-labelled methionine was used to express and detect the BctA protein. The template DNA was: lane A, pBEST/uc; lane B, pVA2320; lane C, pUC19. Size markers are on the left. The protein signal consistent with BctA can be seen in lane $B$ just above the $97.4 \mathrm{kDa}$ marker. Three other protein signals unique to pVA2320 are indicated by the arrows.

First, the antibodies against BctA.2 were tested to determine if they could prevent the conjugative transfer of $\mathrm{pBF} 4$. The rabbit antiserum raised against BctA.2 or against total $B$. fragilis protein containing $\mathrm{pBF} 4$ was added directly to mating mixtures at various concentrations for various durations. The undiluted serum was incubated with the donor cells for $30 \mathrm{~min}$ in a $1: 1$ $(\mathrm{v} / \mathrm{v})$ mixture. The conjugations were allowed to proceed as normal with the addition of either anti-BctA.2, anti-total, or pre-immune serum. B. fragilis V844 containing pBF4 and B. fragilis V503, which contains the conjugative transposon $\operatorname{Tn} 5030$, were used as the positive controls. Initial conjugation-blocking experiments using anti-BctA.2 during a $6 \mathrm{~h}$ mating did not show inhibition or a significant decrease in the transfer of pBF4 as compared to donor cells treated with preimmune serum. To avoid dilution of the antibodies into the agar, or degradation of the antibodies by the 


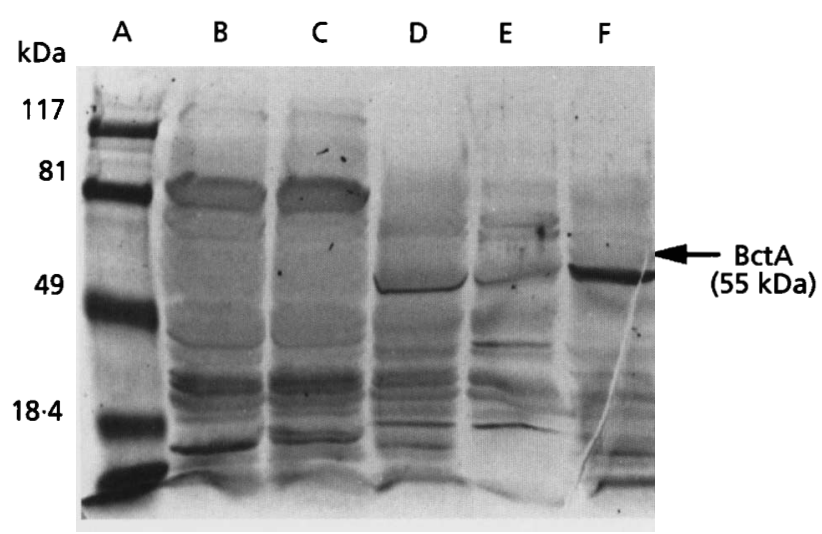

Fig. 5. Western blot analysis of BctA. Protein samples were run on a $10 \%$ Tris/glycine polyacrylamide gel and transferred to nitrocellulose paper. Rabbit antibodies raised against BctA.2 were used as the primary antibody. The bound antibodies were visualized by addition of anti-rabbit Ig $\mathrm{G}$ horseradish peroxidase conjugate, $\mathrm{H}_{2} \mathrm{O}_{2}$ and 4-chloro-1-naphthol. Lane $A$ contains protein molecular mass standards, with their size indicated on the left. Lane B contains total proteins from B. fragilis V844, lane $C$ contains total proteins from $B$. fragilis $V 844$ containing pBF4::pVA2316, and lane D contains total proteins from $B$. fragilis V844 containing pBF4. Lanes E and F contain soluble proteins and membrane-associated proteins, respectively, from B. fragilis V844 containing pBF4. BctA immunoreactive material, presumed to originate from native bct $A$ gene product is indicated by the arrow in the $55 \mathrm{kDa}$ range; this species is seen in both lanes $D$ and $F$.

bacterial strains, fresh antibodies were added every hour and the total mating time was reduced to $3 \mathrm{~h}$. The addition of fresh antibodies and the $3 \mathrm{~h}$ mating time did not have any effect on the transfer of pBF4. Furthermore, the use of antibodies that recognized total proteins from $B$. fragilis containing pBF4 did not inhibit its transfer. A further reduction of the mating time to $1 \mathrm{~h}$, with the addition of fresh antibodies every $15 \mathrm{~min}$, still had no effect on the transfer frequency of pBF4.

The second experiment tested, via fluorescence microscopy, for the ability of antibodies against BctA.2 to bind to whole cells. Three immunological reagents prepared in rabbits were used: anti-BctA.2 antibodies, polyclonal antibodies raised against total proteins from $B$. fragilis V844 containing pBF4, or pre-immune serum. These reagents were mixed separately with various $B$. fragilis strains. After the addition of an anti-rabbit IgG fluorescent antibody, the cells were viewed using fluorescence microscopy. The antibodies raised against total $B$. fragilis proteins uniformly labelled $B$. fragilis V844, $B$. fragilis V844 containing $\mathrm{pBF} 4$, and $B$. fragilis V844 containing pBF4::pVA2316 (data not shown). Neither the pre-immune antiserum nor the antiserum against BctA.2 bound to any of the strains of $B$. fragilis.

\section{DISCUSSION}

We have identified a new bacterial conjugation gene (bct $A)$ that is essential to pBF4-mediated transfer in Bacteroides spp. Previous studies with pBF4 Bacteroides spp. donors have provided general information about the cellular biology of transfer (Odelson et al., 1987; Macrina, 1993). Structural and molecular genetic studies defined a compound transposon carrying the ermF antibiotic-resistance gene on pBF4 (Rasmussen et al., 1986, 1987; Shoemaker et al., 1986). In this work, we applied the technique of recombinational mutagenesis to create mutants of pBF4 which could be evaluated for conjugal transfer proficiency. Although gene transfer among the bacteroides involves conjugative plasmids and conjugative transposons, our ability to genetically manipulate this group has been limited by low transfer efficiencies, the need for a matrix to support mating cells, and a paucity of useful resistance gene markers. Thus we combined $E$. coli recombinant DNA genetics with our ability to mobilize plasmid constructs between E. coli and Bacteroides spp. to create useful mutants for this work.

Because we were unable to use $\operatorname{Tn} 4351$ as a tool to isolate random conjugative-deficient insertion mutants in $\mathrm{pBF} 4$, we adapted insertion-duplication mutagenesis to achieve this goal. Our system was based on a $B$. fragilis-E. coli suicide vector, pVA2200. Six distinct fragments of $\mathrm{pBF} 4 \mathrm{DNA}$ (ranging in size from 0.9 to $2.3 \mathrm{~kb}$ ) were individually cloned into pVA2200 and mobilized into $B$. fragilis V844 containing pBF4 to create six different insertion mutants (Fig. 3). One insert, using a $1.9 \mathrm{~kb}$ HindIII fragment (pVA2316) from the pBF4 EcoRI-A fragment, was found to inhibit the conjugative transfer of $\mathrm{pBF} 4$, indicating the interruption of a conjugative gene (Fig. 3, Table 2). The other five inserts had wild-type conjugative transfer frequencies (Fig. 3, Table 2).

The major advantage of the pVA2200 mutagenesis system is that insertion into pBF4 or other plasmids can be readily controlled. The fragment which drives integration of the construct must be large enough to allow homologous recombination between the two plasmids, and yet small enough to be a subcistronic region of the target gene. If the DNA fragment is larger than the target gene, unwanted duplication of the gene will occur during recombination. We found that the smallest fragment that promoted homologous recombination was 900 bp (data not shown). As described here, the system did have the disadvantage of employing only available restriction fragments. A preferred method of doing large-scale mutagenesis of pBF4 would be the shotgun cloning of uniformly sized random fragments prepared by sonication. Recombinant plasmids then could be mass-mobilized into $B$. fragilis with subsequent selection for co-integrates. This approach affords the recovery of random inserts, allowing for the localization of other pBF4 conjugal transfer genes.

The DNA sequence of the region of $\mathrm{pBF} 4$ that contained the pVA2316 insert was determined. Approximately $7 \cdot 7 \mathrm{~kb}$ of DNA sequence was determined from the $8 \mathrm{~kb}$ PstI-Scal fragment containing the $1.9 \mathrm{~kb}$ HindIII fragment used to create pVA2316 (Fig. 3). A $2 \cdot 8 \mathrm{~kb}$ ORF was identified by computer analysis. This ORF corresponded to the region where integration of pVA2316 and pBF4 
would occur, resulting in its interruption (Fig. 3). This ORF encoded a 946 aa product with a predicted molecular mass of $110 \mathrm{kDa}$. Neither the DNA sequence nor the deduced amino acid sequence shared any similarity to sequences in the GenBank database. Other potential ORFs were identified within the $7.7 \mathrm{~kb}$ of DNA analysed, but their significance has not yet been investigated.

Transfer genes from well-characterized bacterial conjugation systems are linked and coordinately expressed, with an oriT region at one end of the gene cluster (IppenIhler \& Skurray, 1993; Wang \& Macrina, 1995; Lanka $\&$ Wilkins, 1995) It was difficult to evaluate whether the ORFs upstream and downstream of $b c t A$ were involved in conjugation. The pBF4::pVA2200 inserts upstream and downstream of $b c t A$ did not affect transfer phenotype, suggesting that this gene is expressed independently of other conjugation genes. The inserts created by pVA2325 and 2326 would create significant interruptions in the sequences flanking $b c t A$, supporting the notion that this gene is not part of an operon (see Fig. 3 ). Unfortunately, direct testing of the ORFs would not be feasible with the mutagenesis system. For example, there was a $700 \mathrm{bp}$ ORF downstream of $b c t A$. However, this size was too small to create a subcistronic fragment that would result in homologous recombination with pBF4.

Nucleotide sequence similarities between any part of the $7.7 \mathrm{~kb}$ sequence and conserved oriT domains were sought. However, we found that neither of the two conserved oriT domains were similar to any DNA sequence from the $7.7 \mathrm{~kb} \mathrm{pBF} 4$ region. These results indicate that either $\mathrm{pBF} 4$ does not have a conserved oriT domain or the oriT domain is not located on the $7.7 \mathrm{~kb}$ sequenced region of $\mathrm{pBF} 4$. Our attempts to demonstrate a functional oriT site were inconclusive. A pBF4 oriT may need a trans-acting component not encoded on the fragments we tested individually.

Since the $1.9 \mathrm{~kb}$ HindIII fragment used to make pVA2316 was completely internal to the $b c t A$ ORF, it was a good candidate to use as a probe to search for the $b c t A$-like genes. However, the $1.9 \mathrm{~kb}$ HindIII probe did not hybridize to any of the clinical Bacteroides spp. isolates or to the strains with known conjugal elements. These results indicated that $b c t A$ is not involved in all conjugal systems that occur in Bacteroides spp. The uniqueness of $b c t A$ to $\mathrm{pBF} 4$, however, cannot be established until more Bacteroides spp. conjugal elements are examined.

Since $b c t A$ and its protein product appear to be novel, the role BctA plays in the conjugative transfer of pBF4 is unclear. The $\mathrm{pI}$ of the predicted protein is $5 \cdot 3$, indicating that it may be associated with the membrane, although typical stretches of hydrophilic residues alternating with hydrophobic residues were not evident. In addition, the presence of a signal sequence was not observed. To gain a better understanding of the activity of $\mathrm{Bct} A$, rabbit antibodies were raised against a sub-sequence polypeptide (BctA.2) from BctA (Fig. 3). These antibodies were used in Western blot analysis to determine if they would recognize the native BctA from $B$. fragilis containing pBF4. These antibodies recognized a $55 \mathrm{kDa}$ protein that was present in the membrane associated fraction (Fig. 5). The $55 \mathrm{kDa}$ protein was not present in total protein preparations of $B$. fragilis that lacked $\mathrm{pBF} 4$ or $B$. fragilis that contained the pVA2316 insert into pBF4. These results indicate that the expression of the $55 \mathrm{kDa}$ protein was interrupted by the insertion of pVA2316 into pBF4 (Fig. 5). The fact that BctA is associated with the cell membrane is consistent with the predicted $\mathrm{pI}$ of the protein; proteins conferring conjugation from other systems that have a low $\mathrm{pl}$ are found to be associated with the cell membrane (Dempsey, 1993 ; Guiney, 1993 ; Ippen-Ihler \& Skurray, 1993). AntiBctA.2 antibodies failed to inhibit conjugation and they did not specifically bind to donor cells. These mating and fluorescence experiments indicated that either the antibodies to BctA.2 recognized a region of BctA that is not exposed to the environment or that BctA itself is not a surface protein.

The issue of why the immunoreactive $55 \mathrm{kDa}$ protein is so much smaller than the size predicted from the bctA ORF $(110 \mathrm{kDa})$ remains unresolved. Several explanations could account for this, however. First, non-specific proteolysis of the protein may be occurring. Common protease inhibitors did not result in the detection of larger proteins, but these experiments did not rule out proteolysis as the basis of the size difference. Second, BctA may be post-translationally modified (e.g. specific proteolysis) to produce the $55 \mathrm{kDa}$ protein. Finally, it is possible that translation of the message begins at a second start site within the $b c t A$ gene. There are inframe start codons at base-pair coordinates 1188, 1353 and 1410 , which if used as alternative start sites could give rise to a protein in the $52-60 \mathrm{kDa}$ range.

Attempts to immunoprecipitate the $110 \mathrm{kDa}$ protein obtained from the in vitro transcription-translation experiments with the anti-BctA.2 antibodies were unsuccessful (data not shown). This antiserum can now be used to purify the protein from large batches of membrane-associated proteins. Once purified, the primary amino acid sequence of the first five $\mathrm{N}$-terminal residues can be determined thus providing clues as to whether the protein has undergone proteolysis or that an alternative transcription-translation start site was used for its expression.

In addition to identifying the first conjugation-specific gene of $\mathrm{pBF} 4$, the results of this study provide the basis for the further examination of pBF4-mediated conjugation. The development of the mutagenesis system for $\mathrm{pBF} 4$ should allow for further localization of conjugative genes. The characterization of these genes and the elucidation of their function will provide an understanding of the genetic basis of conjugation governed by $\mathrm{pBF} 4$ and related plasmids.

\section{ACKNOWLEDGEMENTS}

This work was supported by US PHS grants R01 DE04224 (to F.L.M.) and P50 DE10703 (to H. A. Schenkein) from the National Institute for Dental Research. 


\section{REFERENCES}

Birnboim, H. C. \& Doly, J. (1979). A rapid alkaline extraction procedure for screening recombinant plasmid DNA. Nucleic Acids Res 7, 1513-1523.

Dempsey, W. B. (1993). Key regulatory aspects of transfer of Frelated plasmids. In Bacterial Conjugation, pp. 53-73. Edited by D. B. Clewell. New York: Plenum Press.

Dower, W. J., Miller, J. F. \& Ragsdale, C. W. (1988). High efficiency transformation of $E$. coli by high voltage electroporation. Nucleic Acids Res 16, 6127-6145.

Fletcher, H. M. \& Macrina, F. L. (1991). Molecular survey of clindamycin and tetracycline resistance determinants in Bacteroides species. Antimicrob Agents Chemother 35, 2415-2418.

Guiney, D. G. (1993). Broad host range conjugative and mobilizable plasmids in Gram-negative bacteria. In Bacterial Conjugation, pp. 75-103. Edited by D. B. Clewell. New York: Plenum Press.

Guiney, D. G., Hasegawa, P. \& Davis, C. E. (1984). Plasmid transfer from Escherichia coli to Bacteroides fragilis: differential expression of antibiotic resistance phenotypes. Proc Natl Acad Sci USA 81, 7203-7206.

Hecht, D. W., Jagielo, T. J. \& Malamy, M. H. (1991). Conjugal transfer of antibiotic resistance factors in Bacteroides fragilis: The $b \operatorname{tg} A$ and $b \operatorname{tg} B$ genes of plasmid pBFTM10 are required for its transfer from Bacteroides fragilis and for its mobilization by IncP $\beta$ plasmid R751 in Escherichia coli. J Bacteriol 173, 7471-7480.

Ippen-Ihler, K. \& Manneewannakul, S. (1991). Conjugation among enteric bacteria: mating systems dependent on expression of pili. In Microbial Cell-Cell Interactions, pp. 35-69. Edited by M. Dworkin. Washington, DC: American Society for Microbiology.

Ippen-Ihler, K. \& Minkley, E. G. (1986). The conjugation system of F, the fertility factor of Escherichia coli. Annu Rev Genetics 20, 593-624.

Ippen-Ihler, K. \& Skurray, R. A. (1993). Genetic organization of transfer-related determinants on the sex factor $F$ and related plasmids. In Bacterial Conjugation, pp. 23-52. Edited by D. B. Clewell. New York: Plenum Press.

Lanka, E. \& Wilkins, B. M. (1995). DNA processing reactions in bacterial conjugation. Annu Rev Biochem 64, 141-169.

Macrina, F. L. (1993). Conjugal transfer in anaerobic bacteria. In Bacterial Conjugation, pp. 331-348. Edited by D. B. Clewell. New York: Plenum Press.

Macrina, F. L., Mays, T. D., Smith, J. C. \& Welch, R. A. (1981). Nonplasmid associated transfer of antibiotic resistance in Bacteroides. J Antimicrob Chemother 8, suppl. D, 77-86.

Matthews, B. G. \& Guiney, D. G. (1986). Characterization and mapping of regions encoding clindamycin resistance, tetracylcine resistance, and a replication function on the Bacteroides $\mathrm{R}$ plasmid pCP1. J Bacteriol 167, 517-521.

Mays, T. D., Smith, C. J., Welch, R. A., Delfini, C. \& Macrina, F. L. (1982). Novel antibiotic resistance transfer in bacteroides. Antimicrob Agents Chemother 21, 110-118.

Novicki, T. J. \& Hecht, D. W. (1995). Characterization and DNA sequence of the mobilization region of pLV22a from Bacteroides fragilis. J Bacteriol 177, 4466-4473.

Odelson, D. A., Rasmussen, J. L., Smith, C. J. \& Macrina, F. L. (1987). Extrachromosomal systems and gene transmission in anaerobic bacteria. Plasmid 17, 87-109.

Privitera, G., Dublanchet, A. \& Sebald, M. (1979). Transfer of multiple antibiotic resistance between subspecies of Bacteroides fragilis. J Infect Dis 139, 97-101.

Rasmussen, J. L., Odelson, D. A. \& Macrina, F. L. (1986). Complete nucleotide sequence and transcription of $\operatorname{ermF}$, a macrolidelincosimide-streptogramin B resistance determinant from Bacteroides fragilis. J Bacteriol 168, 523-533.

Rasmussen, J. L., Odelson, D. A. \& Macrina, F. L. (1987). Complete nucleotide sequence of insertion element IS4351 from Bacteroides fragilis. J Bacteriol 169, 3573-3580.

Salyers, A. A. \& O'Brien, M. (1980). Cellular location of enzymes involved in chondroitin sulfate breakdown by Bacteroides thetaiotaomicron. J Bacteriol 143, 772-780.

Sambrook, J., Fritsch, E. F. \& Maniatis, T. (1989). Molecular Cloning: a Laboratory Manual, 2nd edn. Cold Spring Harbor, NY: Cold Spring Harbor Laboratory.

Shoemaker, N. B., Getty, C., Gardner, J. F. \& Salyers, A. A. (1986). Tn4351 transposes in Bacteroides spp. and mediates the integration of plasmid R751 into the Bacteroides chromosome. J Bacteriol 165, 929-936.

Smith, C. J. (1985). Characterization of Bacteroides ovatus plasmid pBI136 and of its clindamycin resistance region. $J$ Bacteriol 161, 1069-1073.

Smith, C. J., Welch, R. A. \& Macrina, F. L. (1982). Two independent conjugal transfer systems operating in Bacteroides fragilis V479-1. J Bacteriol 151, 281-287.

Tally, F., Snydman, D., Shimell, M. \& Malamy, M. (1982). Characterization of pBFTM10, a clindamycin-erythromycin resistance transfer factor from Bacteroides fragilis. J Bacteriol 151, 686-689.

Wang, A. \& Macrina, F. L. (1995). Streptococcal plasmid pIP501 has a functional oriT site. J Bacteriol 177, 4199-4206.

Welch, R. A. \& Macrina, F. L. (1981). Physical characterization of Bacteroides fragilis $\mathrm{R}$ plasmid pBF4. J Bacteriol 145, 867-872.

Received 15 October 1996; revised 15 February 1997; accepted 19 February 1997. 